\title{
Residues and potential ecological risks of veterinary antibiotics in manures and composts associated with protected vegetable farming
}

\author{
Haibo Zhang • Yongming Luo • Longhua Wu • \\ Yujuan Huang • Peter Christie
}

Received: 31 August 2014 / Accepted: 15 October 2014 / Published online: 30 October 2014

(C) Springer-Verlag Berlin Heidelberg 2014

\begin{abstract}
Veterinary antibiotics (VAs) are emerging contaminants and enter into soil principally by agricultural application of organic fertilizer. A total of 33 solid animal manures and 17 compost samples from protected vegetable farms in nine areas of China were analyzed for the antibiotic classes of tetracyclines, fluoroquinolones, sulfonamides, and macrolides (17 substances in total). Oxytetracycline was found as a dominant compound in the samples, and its highest concentration reached $416.8 \mathrm{mg} \mathrm{kg}^{-1}$ in a chicken manure sample from Shouguang, Shandong Province. Among the samples, animal manures (especially pig manure) contained higher VA residues than composts. However, fluoroquinolones exhibited higher persistence in the compost samples than other antibiotic classes. This is particularly the case in the rice husk compost, which contained the highest level of ofloxacin and ciprofloxacin (1334.5 and $1717.4 \mu \mathrm{g} \mathrm{kg}^{-1}$ on average, respectively). The veterinary antibiotic profile in the risk husk compost had a good relationship with that in the corresponding manures. The refined commercial compost had the lowest VA residues
\end{abstract}

Responsible editor: Leif Kronberg

Electronic supplementary material The online version of this article (doi:10.1007/s11356-014-3731-9) contains supplementary material, which is available to authorized users.

\section{H. Zhang $\cdot$ Y. Luo $(\bowtie)$}

Yantai Institute of Coastal Zone Research, Chinese Academy of Sciences, Yantai 264003, China

e-mail: ymluo@yic.ac.cn

L. Wu $\cdot$ Y. Huang

Key Laboratory of Soil Environment and Pollution Remediation, Institute of Soil Science, Chinese Academy of Sciences,

Nanjing 210008, China

P. Christie

Agri-Food and Biosciences Institute, Newforge Lane, Belfast BT9

5PX, UK among the compost samples in general. This implied that composting process might be important to reduce the antibiotic residue. High residue of antibiotics in soil was assumed to be a hazard to ecosystem. This is especially noticeable under current application rates $\left(150 \mathrm{t} \mathrm{ha}^{-1} \mathrm{a}^{-1}\right)$ in protected vegetable farming because over half of the samples exhibited a risk quotient (RQ) $>1$ for one or more antibiotics.

Keywords Veterinary antibiotics · Manures $\cdot$ Composts · Ecological risk

$\begin{array}{ll}\text { Abbreviations } \\ \text { VAs } & \text { Veterinary antibiotics } \\ \text { TC } & \text { Tetracycline } \\ \text { OTC } & \text { Oxytetracycline } \\ \text { CTC } & \text { Chlortetracycline } \\ \text { DOC } & \text { Doxycycline } \\ \text { SDZ } & \text { Sulfadiazine } \\ \text { SMX } & \text { Sulfamethoxazole } \\ \text { SMZ } & \text { Sulfamethazine } \\ \text { SMM } & \text { Sulfamonomethoxine } \\ \text { SCX } & \text { Sulfachinoxalin } \\ \text { SDM } & \text { Sulfadimethoxine } \\ \text { SM } & \text { Sulfameter } \\ \text { SCZ } & \text { Sulfaclozine } \\ \text { NFC } & \text { Norfloxacin } \\ \text { OFC } & \text { Ofloxacin } \\ \text { CFC } & \text { Ciprofloxacin } \\ \text { EFC } & \text { Enrofloxacin } \\ \text { RTM } & \text { Roxithromycin } \\ \text { SAs } & \text { Sulfonamides } \\ \text { FQs } & \text { Fluoroquinolones } \\ \text { TCs } & \text { Tetracyclines } \\ \text { CC } & \text { Refined commercial compost } \\ \text { RHC } & \text { Rice husk compost } \\ \text { SMC } & \text { Soybean meal compost }\end{array}$




\section{Introduction}

Veterinary antibiotics are used worldwide in livestock and poultry farming to control diseases and promote growth. In the USA, approximately $70 \%$ of the total of 16 million kilograms of antibiotics was estimated to be used in livestock farming annually (Kemper 2008). In the European Union, a total of 1.5 million kilograms of antibiotics has been used as feed additives for growth promotion, accounting for $30 \%$ of the total usage of the antibiotics before the banning of antibiotic usage in animal feeds (Castanon 2007; Sarmah et al. 2006). In China, the use of antibiotics in animal feeds has been regulated since 1989 but many antibiotics are used uncontrolled as feed additives (Jin 1997). The average usage of veterinary antibiotics (VAs) has reached approximately 6000 tons annually and most of this use occurs in the economically developed regions (Zhao et al. 2010). Zhang et al. (2003) have investigated 30 chicken farms in Northeast China and found that the percentage using oxytetracycline and ciprofloxacin in chicken feeds reached 100 and $80 \%$, respectively. However, many antibiotics are poorly absorbed in the gut of the animals, resulting in as much as $30-90 \%$ of the parent compound being excreted via the urine and feces (Sarmah et al. 2006). Thus, a substantial proportion of the antibiotics administered may be released into environment through wastewater discharge or agricultural application of manures.

Application of organic fertilizers to protected vegetable crops is very common in China, and the application rates are much higher than in cereal production or open field vegetable cropping. It has been estimated that $150 \mathrm{t} \mathrm{ha}^{-1}$ of organic fertilizers is applied annually to protected vegetables, ten times the rate of application to open field agricultural crops (Qin et al. 2002). By the end of 2010, the total cropping area of protected vegetables in China had reached 466.7 ha, double the area in 2004 (Yu 2011). This widespread and intensive application of organic fertilizers has been a major pathway for the input of veterinary antibiotics into agricultural soils. Residues of antibiotics have been detected widely in the soils of vegetable land (Hu et al. 2010; Kumar et al. 2005; Li et al. 2011). Some studies have indicated that antibiotics can be taken up by vegetables from soils amended with animal manures and the concentrations of antibiotics in plant tissues increase with amounts of antibiotics in the manures (Hu et al. 2010; Kumar et al. 2005). This may pose a potential human health risk associated with the vegetable consumption. The spread of antibiotic-resistant genes in the environment is assumed to create an even more important risk to human health (Martinez 2008; Pruden et al. 2013; Zhu et al. 2013). Correlations have been found between antibiotic use and the abundance of sulfonamide and tetracycline antibiotic-resistant genes (ARGs) in pig farms and cattle waste lagoons in China (Zhu et al. 2013) and the USA (McKinney et al. 2010), suggesting a relationship between antibiotic use and environmental reservoirs of drug resistance.
Animal manures are a major component of organic fertilizers, and identification of veterinary antibiotics in the manures may be useful in understanding the contribution of organic fertilizer application to antibiotic and resistance genes in areas with intensive protected vegetable production. Several studies have therefore been conducted on the monitoring of veterinary antibiotic residues in samples of animal feces (Chen et al. 2012; Li et al. 2013b; Pan et al. 2011; Zhao et al. 2010). However, organic fertilizers are applied mainly in the form of composts other than the fresh animal manure. Thus, some degradation of antibiotics is likely to occur during the composting, especially during the exothermic stage (Kim et al. 2012). Meanwhile, abiotic reaction with reduced sulfur species could remove the antibiotics from the fresh manures during composting (Zeng et al. 2011, 2012). The objectives of the present study were therefore to identify veterinary antibiotic residues in animal manures and different types of compost and to evaluate the ecological risks associated with the application of organic fertilizers in the protected vegetable farming based on the observed concentrations of antibiotics.

\section{Materials and methods}

\section{Chemicals and standards}

A total of 17 antibiotics were selected as target compounds comprising tetracycline (TC), oxytetracycline (OTC), chlortetracycline (CTC), doxycycline (DOC), sulfadiazine (SDZ), sulfamethoxazole (SMX), sulfamethazine (SMZ), sulfamonomethoxine (SMM), sulfachinoxalin (SCX), sulfadimethoxine (SDM), sulfameter (SM), sulfaclozine (SCZ), norfloxacin (NFC), ofloxacin (OFC), ciprofloxacin (CFC), enrofloxacin (EFC), and roxithromycin (RTM). The deuterated antibiotics, tetracycline-D6, enrofloxacin-D5, sulfamethazine-D4, and sulfadimethoxine-D6, were selected as internal standards. Another two deuterated antibiotics, ciprofloxacin-D8 and sulfamethoxazole-D4, and demeclocycline were selected as surrogate standards. All the standards were purchased from Dr. Ehrenstorfer GmbH, Germany, except for tetracycline-D6 which was obtained from Toronto Research Chemicals Inc., Canada. Methanol and acetonitrile (HPLC grade) were purchased from Merck Company (Darmstadt, Germany); formic acid and oxalic acid and ammonium acetate were purchased from Tedia Company (Fairfield, $\mathrm{OH}$ ) and Sigma-Aldrich (St. Louis, MO), respectively. Other analytical-grade chemicals were obtained from Sinopharm Chemical Reagent Co., Ltd. (Shanghai, China).

Stock solutions of the standards were prepared by dissolving each compound in methanol at a concentration of $100.0 \mathrm{mg} \mathrm{L}^{-1}$ and storing at $-20{ }^{\circ} \mathrm{C}$ in a black volumetric flask. Fresh stock solution was prepared monthly. Working solutions were prepared fresh weekly by diluting the stock 
solution with methanol and storing at $4{ }^{\circ} \mathrm{C}$ in black volumetric flasks. Internal standard working solutions $\left(1.0 \mathrm{mg} \mathrm{L}^{-1}\right)$ were prepared by diluting the standard solution with methanol, storing at $4{ }^{\circ} \mathrm{C}$, and replacing with fresh solution each week.

The $\mathrm{Mg}\left(\mathrm{NO}_{3}\right)_{2}-\mathrm{NH}_{3} \cdot \mathrm{H}_{2} \mathrm{O}$ solution was prepared by mixing the $50 \% \mathrm{Mg}\left(\mathrm{NO}_{3}\right)_{2}$ and $2.5 \% \mathrm{NH}_{3} \cdot \mathrm{H}_{2} \mathrm{O}$ at $96: 4(v /$ v). Sodium phosphate buffer (SPB) was prepared by mixing $10.56 \mathrm{~g}$ of $\mathrm{NaH}_{2} \mathrm{PO}_{4}$ and $0.82 \mathrm{~mL}$ of $\mathrm{H}_{3} \mathrm{PO}_{4}$ in $1 \mathrm{~L}$ water. Ethylenediaminetetraacetic acid-sodium perborate (EDTASPB) ( $\mathrm{pH} 4$ ) was obtained by dissolving $80.0 \mathrm{~g}$ of $\mathrm{Na}_{2}$ EDTA in $1 \mathrm{~L}$ SPB. Ultrapure water was produced by using a Milli-Q apparatus (Millipore, Bedford, MA).

\section{Sample collection}

A total of 50 samples consisting of 33 solid animal manures and 17 composts were collected from the protected vegetable farms situated at nine areas in eight provinces of China (Fig. S1). This type of farm grows vegetables under protective structures (usually plastic house would be used) to shield them from pests and bad weather. The farm also has a high frequency of vegetable rotation even in the low-temperature areas. In order to decrease the influence of manure aging on the antibiotic residue, all the samples were collected from the latest produced batches during the sampling period. Mixed sample was collected and combined from the different stock tanks in a single farm and compost type. The manure samples cover four animal species comprising chickens, ducks, pigs, and cattle, and the three types of compost samples were collected based on their composting process and organic materials. Some refined commercial compost (CC) samples were collected as a representative of well-manufactured composts. The compost was manufactured by mixing manures, organic materials, and fermentative microorganisms and processed with fermentation and pelleting. The fermentation was well controlled under the condition of the appropriate temperature $\left(65-70{ }^{\circ} \mathrm{C}\right)$ and moisture (60-65\%). After the fermentation, the decomposed organic materials were then put into a pelleting machine for granulation followed by cryodrying and sieving. The other two kinds of composts comprising rice husk (RHC) and soybean meal (SMC) were collected as a representative of unsophisticated farm composts. These two composts were processed with fermentation simply at an open field by stacking of animal manures and organic materials (rice husk, soybean meal, etc.). Usually, the temperature and moisture were not controlled strictly. After the fermentation, the compost would be applied to the vegetable field directly.

Each sample was placed in a plastic container, chilled immediately to near freezing, transported to the laboratory, and stored at $-20{ }^{\circ} \mathrm{C}$ in the dark. Before extraction, the samples were freeze-dried in a freeze drying system (Labconco, Kansas City, MO) and homogenized by sieving through a $0.15-\mathrm{mm}$ mesh.
Sample preparation and analysis

Sample preparation and detection were based on our previously developed methods (Huang et al. 2013). Briefly, 0.2-g aliquots of fertilizer samples were weighed into $50-\mathrm{mL}$ polytetrafluoroethene (PTFE) centrifuge tubes and spiked with the surrogate standards and internal standards $\left(100.0 \mu \mathrm{g} \mathrm{kg}^{-1}\right)$. Then, $20 \mathrm{~mL}$ of extraction solvent consisting of EDTA-SPB with acetonitrile/ $\mathrm{Mg}\left(\mathrm{NO}_{3}\right)_{2}-\mathrm{NH}_{3} \cdot \mathrm{H}_{2} \mathrm{O}$ at 3:1 $(v / v)$ was added to each tube and placed in the dark overnight. The sample was extracted by ultra-sonication for $15 \mathrm{~min}$, and the collected extracts were purified and concentrated through an oasis hydrophilic-lipophilic balance (HLB) cartridge. Methanol (10 mL, containing $0.1 \%$ formic acid) was applied to elute the target compounds.

Concentrations of the target antibiotics were determined with an LC-MS/MS system consisting of a Shimadzu LC20AD and triple quadrupole mass spectrometer (API 3200, AB Sciex, Framingham, MA). Separations were performed on a Kromasil C18 column, $5 \mu \mathrm{m}, 250 \times 4.6 \mathrm{~mm}$ (AkzoNobel, Sweden) at a constant temperature of $35^{\circ} \mathrm{C}$. Gradient elution was carried out with water containing $0.1 \%$ formic acid (mobile phase A) and methanol (mobile phase B). The program was as follows: $0-1 \mathrm{~min}, 15 \% \mathrm{~B} ; 1-2 \mathrm{~min}, 15-30 \% \mathrm{~B}$; 2-5 min, 30-40\% B; 5-10 min, 40-50\% B; 10-14 min, 50$70 \% \mathrm{~B} ; 14-16 \mathrm{~min}, 70-100 \% \mathrm{~B}$; and $100 \% \mathrm{~B}$ held for $4 \mathrm{~min}$. The total flow rate was $0.5 \mathrm{~mL} \mathrm{~min}^{-1}$ and the sample injection volume was $10 \mu \mathrm{L}$. The mass spectrometer was set up in positive electrospray ionization (ESI+) mode. Nitrogen gas was used as the drying and collision gas; the electrospray settings were optimized by infusion of separate standard solutions of $1.0 \mathrm{mg} \mathrm{L}^{-1}$ into the ESI+ source at a flow rate of $10 \mu \mathrm{L} \mathrm{min}{ }^{-1}$. Details of the optimized MS operating parameters of the antibiotics are described by Huang et al. (2013). Quantification was performed by internal standard calibration.

\section{Method validation}

The recoveries were investigated by adding standard mixture into a relatively clean sample which has been exposed under UV light to remove possible antibiotics before being used. The samples were divided into two equal aliquots (subsamples A and B). Subsample A was spiked with the standard mixture and subsample B (nonspiked) was used to determine the background concentrations of the analytes, and the recovery was calculated as described in Eq. (1):

Recovery $(\%)=\left(C_{\mathrm{a}}-C_{\mathrm{b}}\right) / C_{\text {spiked }} \times 100$

where $C_{\mathrm{a}}$ and $C_{\mathrm{b}}$ are the measured concentrations of the analyte in subsamples $\mathrm{A}$ and $\mathrm{B}$, respectively, and $C_{\text {spiked }}$ is 
the spiked concentration of the analyte. Here, the spiked concentrations were $50.0,100.0$, and $300.0 \mu \mathrm{g} \mathrm{kg}^{-1}$ with three replicates $(n=3)$ for each. The recoveries of all the target antibiotics in the fertilizer are shown in Table S1 and ranged from 68.8 to $136.0 \%$ on average. Table $\mathrm{S} 1$ also indicates the limit of detection (LOD), limit of quantification (LOQ), and method detection limit (MDL). LOD and LOQ were calculated with signal to noise ratios of 3 and 10 (IUPAC criterion) which ranged from 0.09 to $3.16 \mu \mathrm{g} \mathrm{L}^{-1}$ and 0.49 to $10.5 \mu \mathrm{g} \mathrm{L}^{-1}$, respectively. Determination of MDL was based on the US Environmental Protection Agency (USEPA) method using the variability of seven replicate samples spiked with the native standard mixtures at a level of five times the estimated MDL (USEPA 1999). In order to ensure high quality of the extraction procedure, each sample was spiked with three surrogates (demeclocycline, ciprofloxacin-D8, and sulfamethoxazole-D4) and aged overnight before extraction.

\section{Risk quotient calculation}

The ecological risk of antibiotics for land application was assessed by risk quotient (RQ) (VICH 2004; Li et al. 2013b). The RQ was calculated by Eq. (2):

$\mathrm{RQ}=\frac{\mathrm{PEC}}{\mathrm{PNEC}}$

where PEC $\left(\mu \mathrm{g} \mathrm{kg}^{-1}\right)$ is the predicted environmental concentration based on Eq. (3) and PNEC $\left(\mu \mathrm{gg}^{-1}\right)$ is the predicted no-effect concentration calculated by Eq. (4):

PEC $=\frac{C \times m \times\left(1-\frac{w}{100}\right)}{\rho \times 10 \times \text { depth }}$

$\mathrm{PNEC}=\frac{\mathrm{TOX}}{\mathrm{AF}}$

In Eq. (3), $C\left(\mu \mathrm{g} \mathrm{kg}^{-1}\right)$ is the concentration of antibiotics, $m$ $\left(\mathrm{tha}^{-1}\right)$ is the amount of the fertilizer applied annually and set as $150 \mathrm{t} \mathrm{ha}^{-1}$ (fresh matter weight) based on the data of Qin et al. (2002), and $w$ is the water content (\%) of manures and composts - the water content of chicken, duck, pig, and cattle manures is $38.5,43.1,38.8$, and $33.3 \%$ on average, respectively; as for the compost, the water content of commercial compost, rice husk compost, and soybean meal compost is $15.6,31.6$, and $16.4 \%$ on average, respectively; $\rho\left(\mathrm{kg} \mathrm{m}^{-3}\right)$ is the soil density and set as 1250 based on the average measured value; depth (m) is the soil depth of antibiotics that may be penetrated after fertilizer application and set as $0.2 \mathrm{~m}$; and 10 is a conversion factor. In Eq (4), $\mathrm{TOX}\left(\mu \mathrm{g} \mathrm{kg}^{-1}\right)$ is the toxicity of antibiotics to soil microorganisms and can be substituted with the lowest median effective dose $\left(\mathrm{ED}_{50}\right)$. The $\mathrm{ED}_{50}$ for veterinary antibiotics in soil was sourced from the literature (Jin et al. 2009; Li et al. 2013a; Ma et al. 2013; Thiele-Bruhn 2005; Thiele-Bruhn and Beck 2005). The geometric mean of the $\mathrm{ED}_{50}$ for TC, OTC, CTC, and SDZ was calculated to be the TOX values because the $\mathrm{ED}_{50}$ concentrations of these antibiotics were all derived from the iron(III) reduction test in a same test design (Thiele-Bruhn 2005; Thiele-Bruhn and Beck 2005). While the $\mathrm{ED}_{50}$ based on a root elongation test of Chinese cabbage (Brassica chinensis L.) was used as the TOX value for $\mathrm{CFC}$ because it is the most sensitive species $\mathrm{ED}_{50}$ among the different test species and endpoint (Jin et al. 2009; Li et al. 2013a; Ma et al. 2013). Therefore, the TOX values for TC, OTC, CTC, SDZ, and CFC were 84,832.1, 32,726.5, $16,083.8,29,919.2$, and $1480 \mu \mathrm{g} \mathrm{kg}^{-1}$, respectively. The $\mathrm{ED}_{50}$ values of other antibiotics are not available because of the limited testing results in a real soil system. AF is an assessment factor and set as 1000 for an acute toxicity test or 100 for a chronic toxicity test (Montforts and Verschoor 2003). Here, 1000 was used because all the $\mathrm{ED}_{50}$ values were derived by acute toxicity tests.

\section{Statistical analysis}

Statistical analyses were performed with the software of SPSS 13.0 for Windows. Multiple comparisons of the antibiotic concentrations among the different types of manures and composts and different sampling areas were conducted by one-way ANOVA with LSD method at a significance level of 0.05 .

\section{Results and discussion}

Veterinary antibiotic residues in animal manures

Multiple classes of the veterinary antibiotics (VAs) were detected simultaneously in most of the manures (Table 1). Oxytetracycline, a dominant VA in manures, was detected at the highest concentration of $416.8 \mathrm{mg} \mathrm{kg}^{-1}$ in chicken manure, more than twice the highest concentration reported in China so far (Hu et al. 2010). The geometric mean value of the OTC is $715.3,382.9,1100.5$, and $532.8 \mu \mathrm{g} \mathrm{kg}^{-1}$ in the chicken, duck, pig, and cattle manures, respectively. In addition, the tetracycline (TC) class was found at relatively high concentrations in the manure samples, and its wide occurrence and high residue levels in the animal manures are a cause for concern. In particular, in the pig manure, the concentrations of TC, CTC, and DOC are significantly $(p<0.05)$ higher than those in other types of manures. Among the four fluoroquinolones 


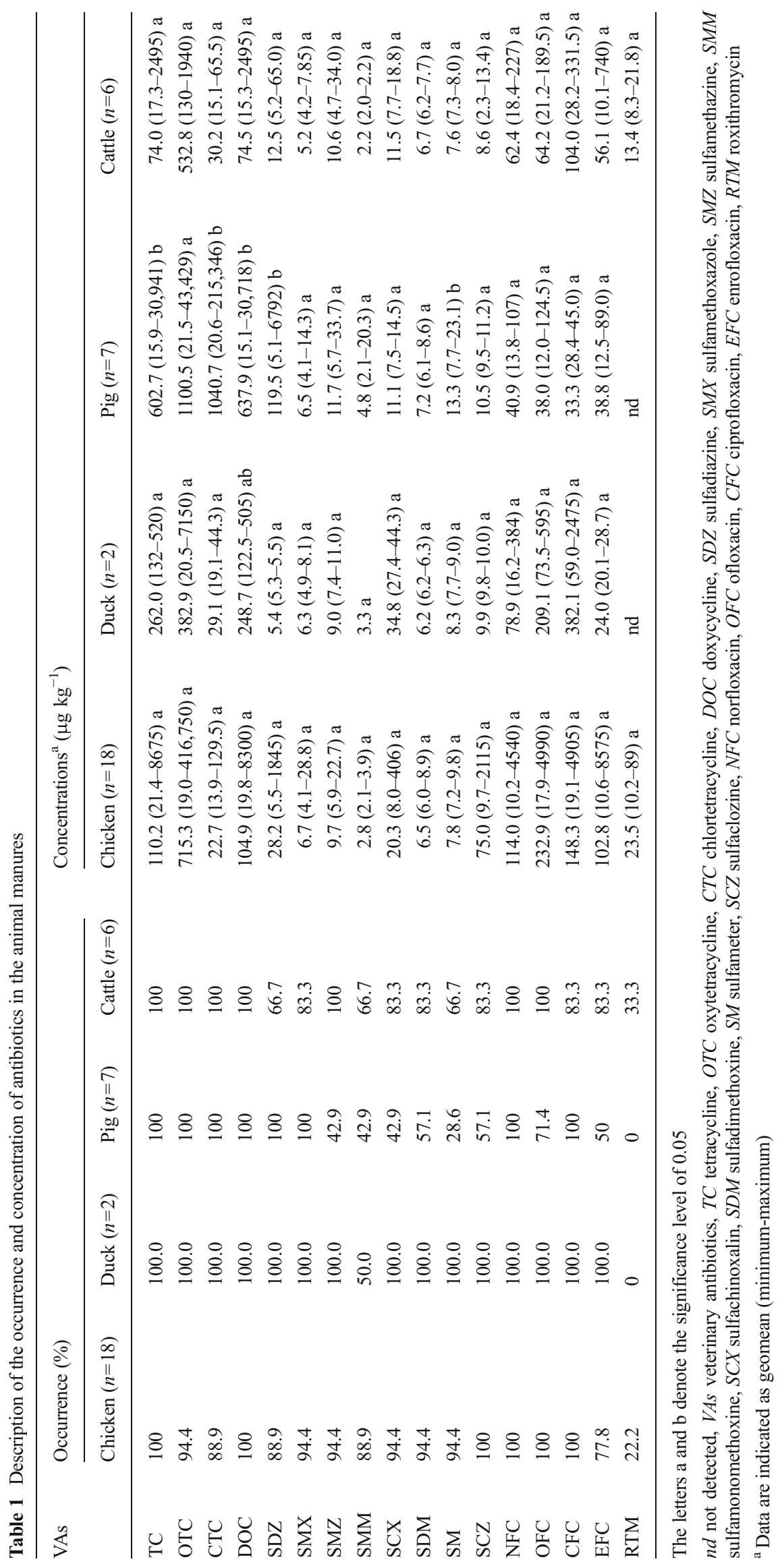


(FQs) determined, enrofloxacin (EFC) was measured at the highest concentration of $8575 \mu \mathrm{g} \mathrm{kg}^{-1}$ in the chicken manure. However, CFC and OFC are the two most important members of the class based on the mean levels. The mean level of CFC is comparable to that of OTC in duck manure as shown in the Table 1. The sulfonamide compounds (SAs) are less prominent than the TCs and FQs, especially in the livestock manures, and their levels are generally lower than those of other antibiotics. However, sulfadiazine (SDZ) and sulfameter (SM) in the pig manures deserved to be noticed because a significant $(p<0.05)$ higher level has been observed in the pig manures compared to other types of manures. Roxithromycin, a macrolide compound, was detected at the lowest occurrence among the 17 antibiotics, and the concentrations were all $<100 \mu \mathrm{g} \mathrm{kg}^{-1}$.

Similar to other studies, TCs and FQs were detected with higher occurrence and higher concentrations than SAs in general. This is assumed to be caused by the differences in physicochemical properties between SAs and TCs and FQs. The organic carbon normalized partition coefficients $\left(K_{\mathrm{oc}}\right)$ of SAs are usually in the range of $48-323 \mathrm{~L} \mathrm{~kg}^{-1}$, but $195-93,320$ and $1100-$ $768,740 \mathrm{~L} \mathrm{~kg}^{-1}$ in TCs and FQs, respectively (ThieleBruhn 2003). This implies that TCs and FQs tend to have higher persistence than SAs in organic matters. The residual levels and species of the antibiotics in manures also showed differences among the animal manure types. The antibiotics in the livestock manures were dominated by TCs, mainly OTC and CTC. The antibiotics in the poultry manures were dominated by TCs and FQs, and the residual levels of FQs were even higher than those in the livestock manures. This suggests that antibiotic usage might be different in animal feeding processing between poultry and livestock, and in addition, the metabolic characteristics of the animals may have some impacts on the antibiotic residues in the manures (Martinez-Carballo et al. 2007; Zhao et al. 2010).

Veterinary antibiotic residues in composts

Substantial quantities of antibiotics were also detected in the compost samples (Table 2). In contrast to the predominant antibiotics of tetracyclines in manure samples, the fluoroquinolones are prominent in the composts. In particular, for the rice husk compost (RHC), it contains the highest level of OFC and CFC among the samples (1334.5 and $1717 \mu \mathrm{g} \mathrm{kg}^{-1}$ on average, respectively). The levels are also significantly $(p<0.01)$ higher than those in other composts (Table 2). This might be related to higher persistence of FQs than TCs and SAs during composting. Selvam et al. (2012) have reported that approximately $17-31 \%$ of spiked CFC remained in contrast to complete removal of CTC and SDZ from the composting mass within the period of composting. In the case of the TCs, the residual level is generally lower than that in the manure samples, however not significantly $(p<0.05)$ different among the three types of composts. This implied that TCs might be degraded substantially during the composting process (Kim et al. 2012; Selvam et al. 2012; Wu et al. 2011). Abiotic transformation of the antibiotics might contribute a great to the degradation during composting. Research has demonstrated that high-organic soils/sediments tend to produce elevated levels of reduced sulfur compounds (e.g., bisulfide and polysulfides) and iron(II) species, which typically possess strong reducing capacity that may degrade veterinary antibiotics faster than microorganisms (Zeng et al. 2011, 2012; Mohatt et al. 2011). Similar to the manures, the SAs concentrations in the composts are lower than other TCs and FQs generally; however, SDZ in the soybean meal compost (SMC) and SCX in the rice husk compost (RHC) are prominent due to their significant higher level in the two composts. The highest residual level of SDZ in the soybean meal compost (SMC) is $10,400 \mu \mathrm{g} \mathrm{kg}^{-1}$ (Table 2), which is much higher than that in the manure, and the reason needs to be investigated further.

The selected composts were made of different raw materials (including manures and organic materials) and by different composting processes. Antibiotic residues in the commercial compost (CC) were generally lower than those in the other four composts (Table 2). The CC was subjected to the processes of decomposition, dehydration, and sterilization, but the other two composts were subjected mainly to a decomposition process with addition of organic materials (rice husk, soybean meal, etc.) (Liu et al. 2005). Therefore, the antibiotic residues were assumed to be impacted by the different composting processes based on our preliminary investigation; however, it was necessary to be verified by further experiments. In addition, manure sources of the compost might have an impact on the antibiotic residue in the compost. Figure 1 shows the different antibiotic residues between chicken-RHC and cattle-RHC which are produced with chicken manure and cattle manure, respectively. The antibiotics in chicken-RHC are characterized by higher FQs and lower TCs compared with those in cattle-RHC, in accordance with the different characteristics of antibiotic residue between the chicken manure and cattle manure. This implies that antibiotic residual characteristics in the compost can probably be traced back to the residue in the manures for the compost producing (Wu et al. 2011).

\section{Effect of sampling region on residual levels}

Comparisons of antibiotic residues among the different regions were evaluated for poultry manure and commercial compost separately by using concentrations of each class of 
Table 2 Description of the occurrence and concentration of antibiotics in the composts

\begin{tabular}{|c|c|c|c|c|c|c|}
\hline \multirow[t]{2}{*}{ VAs } & \multicolumn{3}{|c|}{ Occurrence (\%) } & \multicolumn{3}{|c|}{ Concentrations $^{\mathrm{a}}\left(\mu \mathrm{g} \mathrm{kg}^{-1}\right)$} \\
\hline & $\mathrm{CC}(n=10)$ & $\mathrm{RHC}(n=3)$ & $\operatorname{SMC}(n=4)$ & $\mathrm{CC}(n=10)$ & $\mathrm{RHC}(n=3)$ & $\operatorname{SMC}(n=4)$ \\
\hline $\mathrm{TC}$ & 90.0 & 66.7 & 100 & $55.3(13.2-3700) \mathrm{a}$ & $72.9(22.6-235) \mathrm{a}$ & $25.2(18.5-36.5) \mathrm{a}$ \\
\hline OTC & 100 & 100 & 100 & $138.6(9.1-680)$ a & $76.1(10.5-334) \mathrm{a}$ & $106.7(35.8-192.5) \mathrm{a}$ \\
\hline CTC & 100 & 100 & 100 & $29.8(14.7-155.5) \mathrm{a}$ & $32.2(16.4-46.9) \mathrm{a}$ & $24.6(16.6-41.9) \mathrm{a}$ \\
\hline $\mathrm{DOC}$ & 90.0 & 100 & 100 & $55.8(12.4-3685) \mathrm{a}$ & $34.0(9.4-229.5) \mathrm{a}$ & $25.5(15.5-35.3) \mathrm{a}$ \\
\hline SDZ & 90.0 & 66.7 & 100 & $10.6(5.3-32.9) \mathrm{a}$ & $5.2(5.1-5.3) \mathrm{a}$ & $263.4(5.1-10,400) b$ \\
\hline SMX & 100 & 66.7 & 100 & $7.0(4.5-14.8) \mathrm{a}$ & $5.1(4.4-5.8) \mathrm{a}$ & $7.2(4.8-10.9) \mathrm{a}$ \\
\hline SMZ & 100 & 100 & 100 & $15.2(6.6-71.0) \mathrm{a}$ & $7.6(6.5-8.7) \mathrm{a}$ & $26.7(15.2-78.5) \mathrm{a}$ \\
\hline SMM & 90.0 & 100 & 100 & $3.9(2.1-15.7) \mathrm{a}$ & $4.5(2.0-22.2) \mathrm{a}$ & $3.9(2.4-11.1) \mathrm{a}$ \\
\hline SCX & 90.0 & 100 & 100 & $10.3(7.8-14.5) \mathrm{a}$ & $17.2(8.1-43.4) b$ & $12.5(8.8-16.3) \mathrm{ab}$ \\
\hline SDM & 100 & 100 & 100 & $6.4(6.0-7.8) \mathrm{a}$ & $6.3(6.2-6.5) \mathrm{a}$ & $6.3(6.1-6.7) \mathrm{a}$ \\
\hline SM & 100 & 100 & 100 & $8.2(7.2-12.2) \mathrm{a}$ & $11.6(7.3-29.3) \mathrm{a}$ & $8.4(7.7-9.4) \mathrm{a}$ \\
\hline $\mathrm{SCZ}$ & 100 & 100 & 100 & $18.4(9.6-348.8) \mathrm{a}$ & $27.6(9.4-90.0)$ a & $18.7(11.8-37.4) \mathrm{a}$ \\
\hline $\mathrm{NFC}$ & 100 & 100 & 100 & $89.4(9.8-3565)$ a & $23.0(10.0-43.7) \mathrm{a}$ & $227.3(115.5-473.5) \mathrm{a}$ \\
\hline OFC & 100 & 100 & 100 & $82.4(11.8-2282) \mathrm{a}$ & $1334.5(315.0-7900) b$ & $139.3(77.5-635) \mathrm{a}$ \\
\hline $\mathrm{CFC}$ & 90.0 & 100 & 100 & $82.8(17.8-2395)$ a & $1717.4(376.5-5750) b$ & $132.8(46.6-295) \mathrm{a}$ \\
\hline $\mathrm{EFC}$ & 70.0 & 100 & 100 & $40.3(8.8-1540)$ a & $184.6(61.0-1505) \mathrm{a}$ & $75.9(14.9-487) \mathrm{a}$ \\
\hline RTM & 10.0 & 33.3 & 0 & $51.5 \mathrm{a}$ & $46.7 \mathrm{a}$ & nd \\
\hline
\end{tabular}

The letters $\mathrm{a}$ and $\mathrm{b}$ denote the significance level of 0.05

nd not detected, VAs veterinary antibiotics, TC tetracycline, OTC oxytetracycline, CTC chlortetracycline, DOC doxycycline, SDZ sulfadiazine, SMX sulfamethoxazole, $S M Z$ sulfamethazine, $S M M$ sulfamonomethoxine, $S C X$ sulfachinoxalin, $S D M$ sulfadimethoxine, $S M$ sulfameter, $S C Z$ sulfaclozine, $N F C$ norfloxacin, $O F C$ ofloxacin, $C F C$ ciprofloxacin, $E F C$ enrofloxacin, $R T M$ roxithromycin, $C C$ refined commercial compost, $R H C$ rice husk compost, $S M C$ soybean meal compost

${ }^{a}$ Data are indicated as geomean (minimum-maximum)

antibiotic. To facilitate the statistical analysis, areas with sample numbers $\geq 3$ were selected.

As shown in Fig. 2, regional differences in antibiotic residues are evident for both poultry manure and commercial compost. In the manure samples, TC concentration exhibited a significant $(p<0.05)$ difference among the three sampling areas. The highest average concentration could be found in the poultry manure of Shouguang, Shandong Province. The SAs and FQs are shown to have no statistical difference among the three sampling areas. In the compost samples, SA
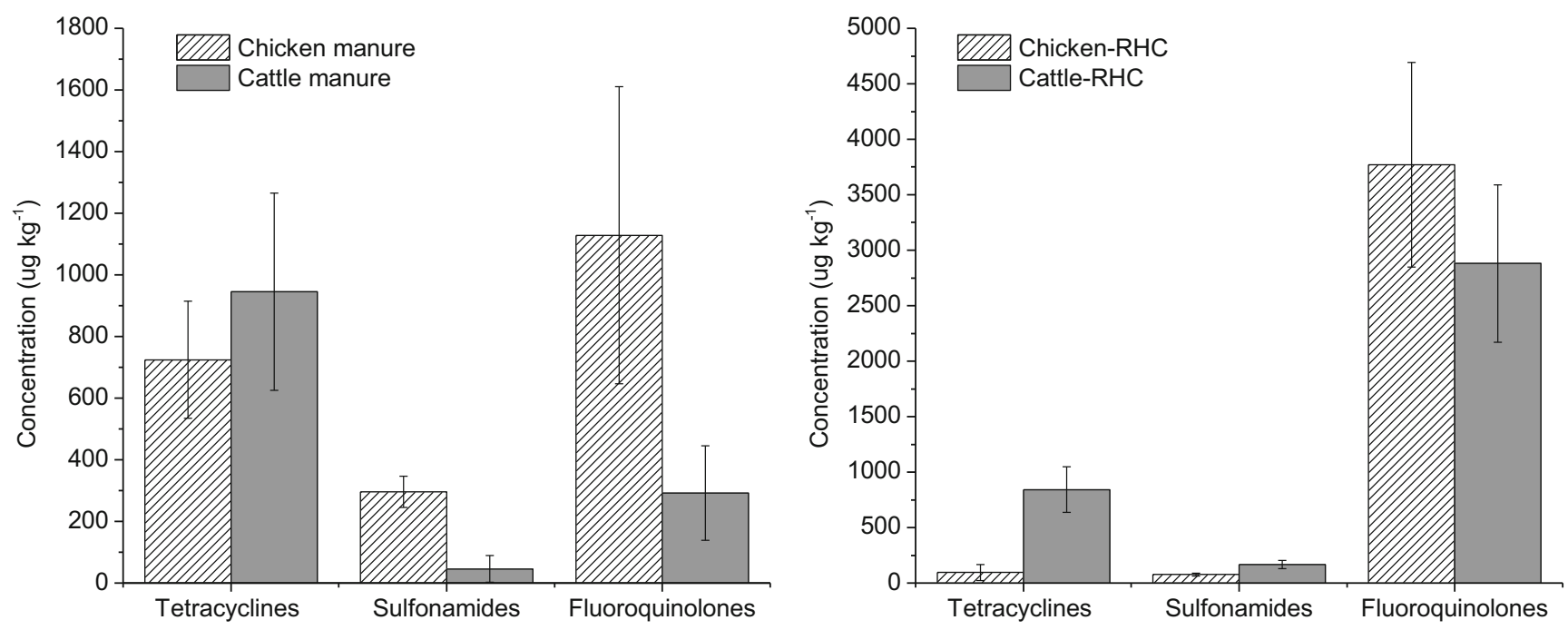

Fig. 1 Antibiotic residues in the chicken and cattle manures and the rice husk compost made of chicken and cattle manures 

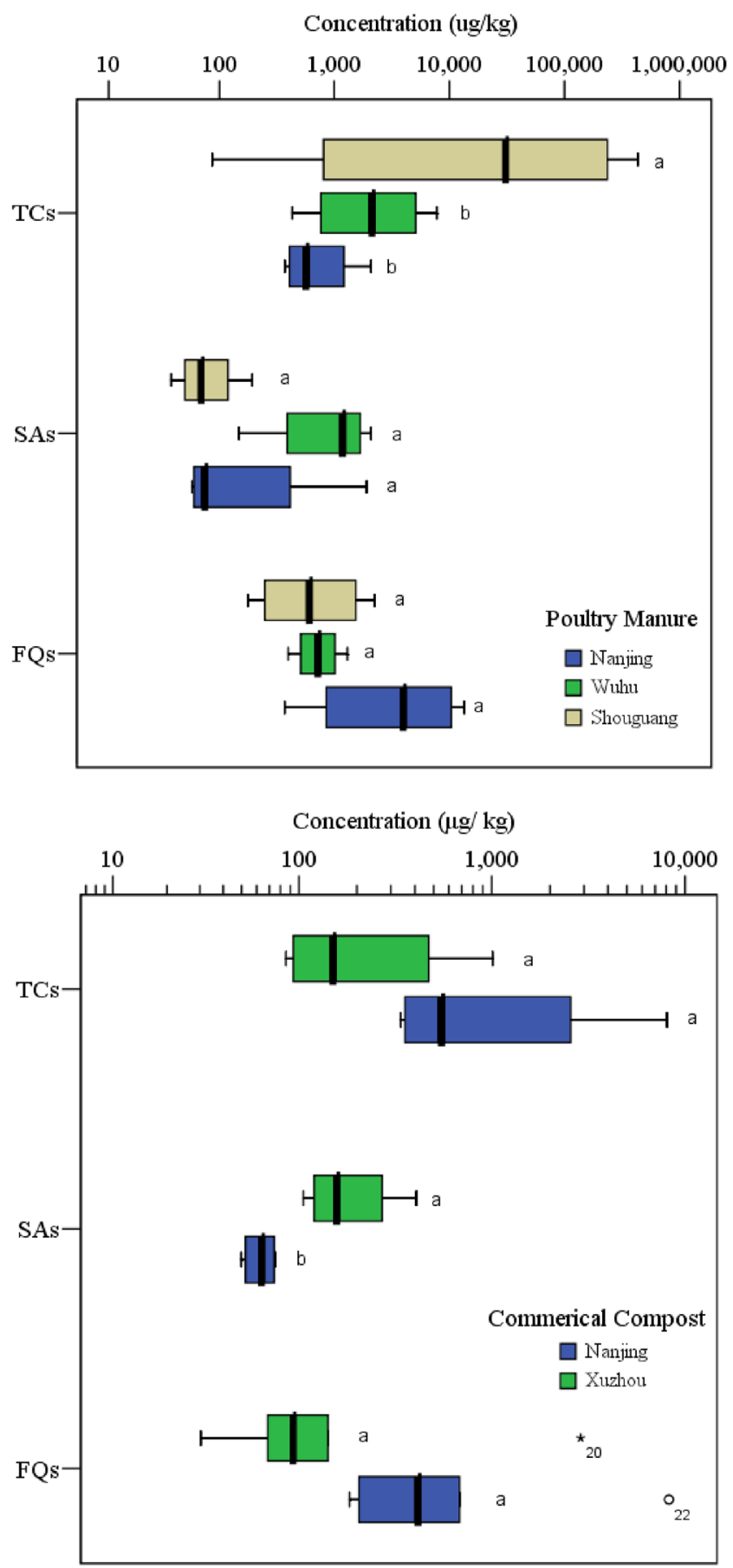

Fig. 2 Box plots indicating the regional differences of the antibiotic residues in the animal manures and the composts. TCs tetracyclines, summarized by tetracycline, oxytetracycline, chlortetracycline and doxycycline; $S A s$ sulfonamides, summarized by sulfadiazine, sulfamethoxazole, sulfamethazine, sulfamonomethoxine, sulfachinoxalin, sulfadimethoxine, sulfameter, and sulfaclozine; $F Q s$ fluoroquinolones, summarized by norfloxacin, ofloxacin, ciprofloxacin, and enrofloxacin. $a$ and $b$ denote the significance level of 0.05 . $* 20$ and ${ }^{\circ} 20$ indicated the outlier of the dataset

concentration exhibited a significant $(p<0.05)$ difference between Nanjing and Xuzhou, both in Jiangsu Province. The commercial compost of Xuzhou had a higher SAs residue than that of Nanjing. The other two classes of the antibiotics are shown to have no statistical difference between the two areas. Shouguang in Shandong Province and $\mathrm{Xu}-$ zhou in Jiangsu Province are both famous for their protected vegetable farming in China and for applying a large amount of manure and compost as organic fertilizers (Pan et al. 2011; Zhao et al. 2010). Meanwhile, large-scale livestock and poultry production units were established in these areas earlier than in other regions (Liu et al. 2002; Zhang et al. 2007), which provided majority of the manures and composts for the vegetable farming. Li et al. (2013b) have observed based on statistical analysis that large-scale concentrated animal feeding operations (CAFO) tended to use a wider range and higher dosages of veterinary antibiotics compared to the small-scale CAFO, resulting in higher contamination of feces with antibiotics.

\section{Potential risk assessment for land application}

Inhibition of microorganisms in relation to iron(III) reduction by tetracycline and sulfadiazine has been found in soils, and the $\mathrm{ED}_{50}$ (dosage at a $50 \%$ of inhibition) ranged from 2.7 to $231.1 \mathrm{mg} \mathrm{kg}^{-1}$ and from 5.3 to $182.7 \mathrm{mg} \mathrm{kg}^{-1}$, respectively (Thiele-Bruhn 2005; Thiele-Bruhn and Beck 2005). A few studies have tested the toxic effects of ciprofloxacin on seed germination and root elongation of Chinese cabbage (Brassica chinensis L.), radish (Raphanus Sativus L.), and maize (Zea mays $\mathrm{L}$.). The $\mathrm{ED}_{50}$ of these test species ranged from 1.48 to $11.23 \mathrm{mg} \mathrm{kg}^{-1}$ (Jin et al. 2009; Li et al. 2013a; Ma et al. 2013). Therefore, risk quotient (RQ) was applied to evaluate the potential ecological risks associated with the agricultural application of the organic fertilizers in protected vegetable land. The value of $R Q>1$ was supposed to be incidence of the potential risks, and further assessment needs to be done (VICH 2004).

More than half the collected organic fertilizers might pose a potential ecological risk due to the presence of at least one compound after land application under current loading rates (150 t ha $\mathrm{ha}^{-1} \mathrm{a}^{-1}$, fresh weight). A higher risk was shown in animal manures than in composts, corresponding to the antibiotic residue levels (Fig. 3). As for the animal manures, the potential risks are prominent due to OTC, TC, and CFC individually or in combination in manures of the four animal species (chickens, ducks, pigs, and cattle). The risk from CTC occurs mainly in pig manures due to their elevated CTC residues. A few chicken and pig manures also show risk from SDZ. As for the composts, CFC has a higher risk than other compounds and occurs in the three types of composts. The risk in relation to the combination of tetracyclines and fluoroquinolones deserves attention in the commercial composts because they might have a synergistic inhibitory effect on soil organisms (Migliore 
Fig. 3 Hazard quotient (HQ) indicating risks associated with land application of the animal manures and composts
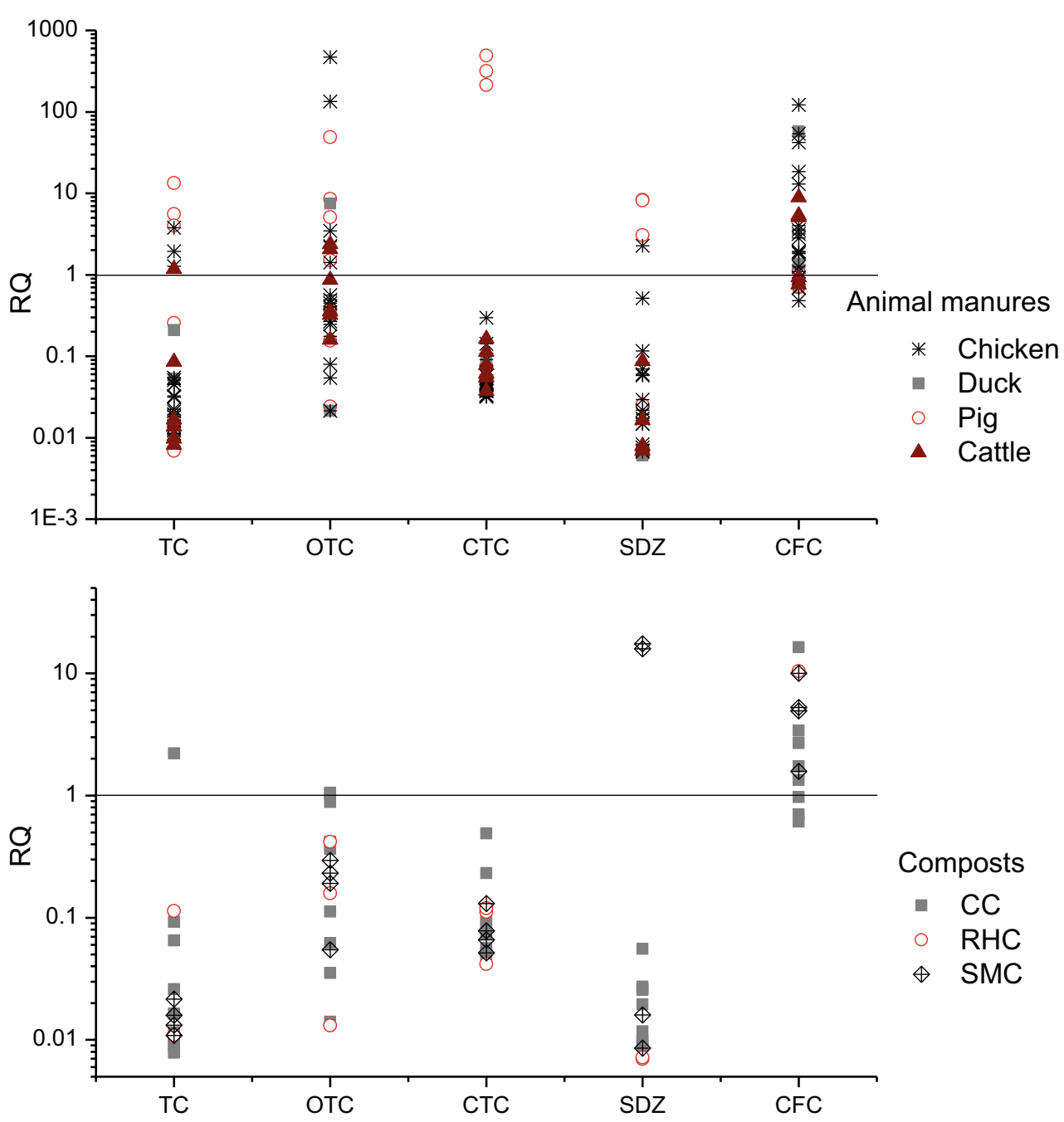

Veterinary Antibiotics et al. 1997). Besides CFC, the risk of SDZ is a concern when applying soybean meal compost in the vegetable fields due to the high RQ value of SDZ. Overall, the composts were relatively safe compared with the animal manures.

\section{Conclusions}

Residues of veterinary antibiotics in the animal manures and composts were ubiquitous as confirmed by the wide occurrence of the 17 antibiotics in the samples collected. Oxytetracycline residue levels were as high as $416.8 \mathrm{mg} \mathrm{kg}^{-1}$ in the chicken manure sample, the highest level ever reported for manure in China. Antibiotic contamination was more severe in the animal manures than in the composts in general, and pig manures exhibited the highest tetracycline residue among the four types of manures. In the case of the composts, the rice husk compost (RHC) exhibited the highest residue of fluoroquinolones; however, residue of antibiotics in the compost was associated with the sourced manures. In addition, the composting process probably had an important role on the antibiotic residue in the compost, which could be partially supported by the fact that the refined commercial compost contained the lowest residue level of the antibiotics in general. This implied that the reduction of antibiotic residue in the manures could be achieved by proper composting (such as under high temperature and ventilation condition). However, the higher persistence of fluoroquinolones in the compost deserves to be of concern in the future. High residue of antibiotics in the manures and composts could probably cause risks to the soil ecosystem after they were applied on the protected vegetable fields with a certain amount (such as $150 \mathrm{t} \mathrm{ha}^{-1} \mathrm{a}^{-1}$ ). Therefore, it is 
necessary to limit the amount of organic fertilizer application based on the containing toxic chemicals in order to reduce the associated risks to ecosystems and human health.

Acknowledgments This research was supported financially by the National Natural Science Foundation of China (41371313 and 41230858) and the R\&D Special Fund for Public Welfare Industry (Environment) (201109018-4). We appreciate the two anonymous reviewers for their comments on the paper's revision.

\section{References}

Castanon JI (2007) History of the use of antibiotic as growth promoters in European poultry feeds. Poult Sci 86:2466-2471

Chen YS, Zhang HB, Luo YM, Song J (2012) Occurrence and assessment of veterinary antibiotics in swine manures: a case study in East China. Chin Sci Bull 57:606-614

Hu XG, Zhou QX, Luo Y (2010) Occurrence and source analysis of typical veterinary antibiotics in manure, soil, vegetables and groundwater from organic vegetable bases, northern China. Environ Pollut 158:2992-2998

Huang YJ, Cheng MM, Li WH, Wu LH, Chen YS, Luo YM, Christie P, Zhang HB (2013) Simultaneous extraction of four classes of antibiotics in soil, manure and sewage sludge and analysis by liquid chromatography-tandem mass spectrometry with the isotopelabelled internal standard method. Anal Methods 5:3721-3731

Jin S (1997) Regulation, realities and recommendation on antimicrobial use in food animal production in China. The medical impact of the use of antimicrobials in food animals. Geneva: WHO; Section 2.3.4

Jin C, Chen Q, Liu J, Zhou Q (2009) The eco-toxicological effect of two common veterinary drugs on crop germination. Acta Sci Circumst 29:619-625

Kemper N (2008) Veterinary antibiotics in the aquatic and terrestrial environment. Ecol Indic 8:1-13

Kim KR, Owens G, Ok YS, Park WK, Lee DB, Kwon SI (2012) Decline in extractable antibiotics in manure-based composts during composting. Waste Manag 32:110-116

Kumar K, Gupta SC, Baidoo SK, Chander Y, Rosen CJ (2005) Antibiotic uptake by plants from soil fertilized with animal manure. J Environ Qual 34:2082-2085

Li YW, Wu XL, Mo CH, Tai YP, Huang XP, Xiang L (2011) Investigation of sulfonamide, tetracycline, and quinolone antibiotics in vegetable farmland soil in the Pearl River Delta Area, Southern China. J Agric Food Chem 59:7268-7276

Li T, Jin C, Zhu W, Liu G, Liu H, Zheng L (2013a) Toxicity of ciprofloxacin to three crops. Asian J Ecotoxicol 8:442-446

Li YX, Zhang XL, Li W, Lu XF, Liu B, Wang J (2013b) The residues and environmental risks of multiple veterinary antibiotics in animal faeces. Environ Monit Assess 185:2211-2220

Liu P, Chen Z, Xu S, Liu J (2002) Waste loading and treatment strategies on the excreta of domestic animals in the Yangtze Delta. Res Environ Yangtze Basin 11:456-460

Liu RL, Li ST, Wang XB, Wang M (2005) Contents of heavy metals in commercial organic fertilizers and organic wastes. J Agro-Environ Sci 24:392-397

Ma Y, Peng J, Wang Y, Chen F, Chen J, Sun Y (2013) Effects of ciprofloxacin on microbial biomass carbon and carbon metabolism diversity of soil microbial communities. Acta Ecol Sin 33:15061512

Martinez JL (2008) Antibiotics and antibiotic resistance genes in natural environments. Science 321:365-367
Martinez-Carballo E, Gonzalez-Barreiro C, Scharf S, Gans O (2007) Environmental monitoring study of selected veterinary antibiotics in animal manure and soils in Austria. Environ Pollut 148:570-579

McKinney CW, Loftin KA, Meyer MT, Davis JG, Pruden A (2010) tet and sul antibiotic resistance genes in livestock lagoons of various operation type, configuration, and antibiotic occurrence. Environ Sci Technol 44:6102-6109

Migliore L, Civitareale C, Brambilla G, DiDelupis GD (1997) Toxicity of several important agricultural antibiotics to Artemia. Water Res 31: 1801-1806

Mohatt JL, Hu LH, Finneran KT, Strathmann TJ (2011) Microbially mediated abiotic transformation of the antimicrobial agent sulfamethoxazole under iron-reducing soil conditions. Environ Sci Technol 45:4793-4801

Montforts MHMM, Verschoor AJ (2003) Environmental risk assessment for veterinary medicinal products: Part 3. Validation of environmental exposure models. The National Institute for Public Health and the Environment (RIVM), BV Bilthoven

Pan X, Qiang ZM, Ben WW, Chen MX (2011) Residual veterinary antibiotics in swine manure from concentrated animal feeding operations in Shandong Province, China. Chemosphere 84:695-700

Pruden A, Larsson DG, Amezquita A, Collignon P, Brandt KK, Graham DW, Lazorchak JM, Suzuki S, Silley P, Snape JR, Topp E, Zhang T, Zhu YG (2013) Management options for reducing the release of antibiotics and antibiotic resistance genes to the environment. Environ Health Perspect 121:878-885

Qin QY, Jia CZ, Qu D, Tong YA, Wang RT (2002) Advances and characters of fertilizer application of protected field agriculture in China. J Hubei Agric College 22:373-376

Sarmah AK, Meyer MT, Boxall AB (2006) A global perspective on the use, sales, exposure pathways, occurrence, fate and effects of veterinary antibiotics (VAs) in the environment. Chemosphere 65:725759

Selvam A, Zhao ZY, Wong JWC (2012) Composting of swine manure spiked with sulfadiazine, chlortetracycline and ciprofloxacin. Bioresour Technol 126:412-417

Thiele-Bruhn S (2003) Pharmaceutical antibiotic compounds in soils-a review. J Plant Nutr Soil Science-Zeitschrift Fur Pflanzenernahrung Und Bodenkunde 166:145-167

Thiele-Bruhn S (2005) Microbial inhibition by pharmaceutical antibiotics in different soils - dose-response relations determined with the iron(III) reduction test. Environ Toxicol Chem 24: 869-876

Thiele-Bruhn S, Beck IC (2005) Effects of sulfonamide and tetracycline antibiotics on soil microbial activity and microbial biomass. Chemosphere 59:457-465

USEPA (1999) Protocol for EPA approval of new methods for organic and inorganic analytes in wastewater and drinking water. In: USEPA (Ed.), Washington, DC 20460

VICH (2004) The European Agency for the Evaluation of Medicinal Products: environmental impact assessment for veterinary medicinal products. Phase II guidance. VICH Topic GL 38 (Ecotoxicity Phase II) Step 7 (CVMP/VICH/790/03-Final)

Wu XF, Wei YS, Zheng JX, Zhao X, Zhong WK (2011) The behavior of tetracyclines and their degradation products during swine manure composting. Bioresour Technol 102:59245931

Yu JQ (2011) Progress in protected vegetable production and research during "The Eleventh Five-year Plan" in China. China Vegetables 2: $11-23$

Zeng T, Ziegelgruber KL, Chin YP, Arnold WA (2011) Pesticide processing potential in prairie pothole porewaters. Environ Sci Technol 45:6814-6822

Zeng T, Chin YP, Arnold WA (2012) Potential for abiotic reduction of pesticides in prairie pothole porewaters. Environ Sci Technol 46:3177-3187 
Zhang L, Fu XZ, Yao Y (2003) The residuals of hormone and antibiotics in the commercial chicken in Harbin and its management measures. Chin J Publ Health Manag 19:464

Zhang XM, Dong YH, Wang H, Sheng D (2007) Structure of livestock and variation of fecal nitrogen pollution load in China. Environ Sci 28:1311-1318
Zhao L, Dong YH, Wang H (2010) Residues of veterinary antibiotics in manures from feedlot livestock in eight provinces of China. Sci Total Environ 408:1069-1075

Zhu YG, Johnson TA, Su JQ, Qiao M, Guo GX, Stedtfeld RD, Hashsham SA, Tiedje JM (2013) Diverse and abundant antibiotic resistance genes in Chinese swine farms. Proc Natl Acad Sci U S A 110:34353440 